\title{
Clinical Relevance of Postoperative Neutrophil-Lymphocyte Ratio (NLR) to Recurrence After Adjuvant Chemotherapy of S-1 for Gastric Cancer
}

\author{
HIROAKI TANAKA, TATSURO TAMURA, TAKAHIRO TOYOKAWA, KAZUYA MUGURUMA, \\ YUICHIRO MIKI, NAOSHI KUBO, KATSUNOBU SAKURAI, KOSEI HIRAKAWA and MASAICHI OHIRA \\ Department of Surgical Oncology, Osaka City University Graduate School of Medicine, Osaka, Japan
}

\begin{abstract}
Background/Aim: The clinical significance of postoperative neutrophil lymphocyte ratio (NLR) remains unclear. The aim of this study was to examine the impact of postoperative NLR on prediction for postoperative recurrence of gastric cancer. Patients and Methods: A retrospective analysis was performed on data from 170 patients with Stage II/III gastric cancer who underwent surgery followed by adjuvant chemotherapy using $S-1$ between 2006 and 2015. Postoperative NLR was calculated every 6 months and the data at the time of recurrence or last survival were used for analysis. Results: Postoperative NLR was associated with Prognostic nutritional index (PNI) and modified Glasgow Prognostic Score (mGPS). In multivariate analysis, we found that elevated CA19-9, CEA and NLR were independent predictive markers. The patients with low values of both NLR and CEA after surgery had the most favorable prognosis. Conclusion: The postoperative NLR might be one of the surrogate markers for recurrence after curative surgery for patients with Stage II/III gastric cancer.
\end{abstract}

Postoperative adjuvant chemotherapy using S-1 is a standard therapy for patients with Stage II/III gastric cancer in Japan based on the results of the Adjuvant Chemotherapy Trial of S-1 for Gastric Cancer (ACTS-GC study) (1). As shown in the ACTS-GC study, S-1 is generally administered for one year after surgery though the completion rate remains $70 \%$ and the prognosis of the patients that were not able to complete it was poor (2). The 5-year postoperative survival rates for stage II was $70 \%, 54 \%$ for stage IIIA and $36 \%$ for stage IIIB (3). It is necessary to predict relapse early, and

Correspondence to: Hiroaki Tanaka, 1-4-3 Asahi-machi, Abeno-ku, Osaka 545-8585, Japan. Tel: +81 666453838, Fax: +81 666466450, e-mail: hiroakitan@med.osaka-cu.ac.jp

Key Words: Gastric cancer, adjuvant chemotherapy, neutrophillymphocyte ratio. shift to second-line effective chemotherapy $(4,5)$. To predict recurrence, serum tumor markers including carcinoembryonic antigen (CEA) and carbohydrate antigen 19-9 (CA19-9) are monitored after surgery (6).

The neutrophil-lymphocyte ratio (NLR) is one of the most common hematologic parameters reflecting systemic inflammation and survival of patients with cancer (7). Neutrophils have the capacity of inducing angiogenesis, inflammation and pro-tumor immune response (8). Lymphocytes are linked to tumor-infiltrative $\mathrm{T}$ lymphocytes which are the most important mediators of an anti-tumor immune response (9). Therefore, it is hypothesized that NLR might reflect the balance of inflammation and immune reaction in the tumor microenvironment. NLR was one of the predictive factors for patients with colorectal cancer, pancreatic cancer, esophageal cancer and gastric cancer (1013). The significance of NLR on the effect of postoperative adjuvant chemotherapy remains unclear though reports focused on the relationship of NLR with chemotherapy for advanced gastric cancer. For example, it has been reported that the PFS and OS of patients with a low NLR were significantly longer than in patients with a high NLR in a Korean study of the combination of paclitaxel with ramcirumab (14).

The aim of this study was to examine the impact of postoperative NLR on recurrent diseases after adjuvant chemotherapy using S-1 for patients with gastric cancer.

\section{Patients and Methods}

Patients. Data were obtained from 170 patients with histologically confirmed gastric cancer who had undergone gastrectomy with lymph node dissection followed by adjuvant chemotherapy using S1 between 2006 and 2015 at Department of Surgical Oncology of Osaka City University. Stage and other information including macroscopic types, histology, depth of tumor (T), lymph node metastasis $(\mathrm{N})$, distant metastasis (M), lavage cytology (CY), lymphatic or venous involvement were classified according to the criteria of the 3rd edition of Japanese Gastric Cancer Association 
(15). Laboratory data including full blood count (neutrophils, lymphocytes, platelets, albumin, CRP, carcinoembryonic antigen (CEA) and CA19-9) were collected at the time of pre-surgery, 1 month, 6 months, 12 months and 18 months after surgery. Prognostic nutritional index (PNI) was calculated using the formula: $10 \times$ albumin $(\mathrm{g} / \mathrm{dl})+0.005 \times$ lymphocyte $\left(/ \mathrm{mm}^{3}\right)$. The mGPS was constructed as previously described (16). Patients who received induction chemotherapy before surgery were excluded to remove the influence of chemotherapy.

S-1 chemotherapy. The patients received S-1 orally twice daily for the first 4 weeks of a 6-week cycle. Schedule change of 2 weeks on and 1 week off etc. was permitted. The dose of S-1 administered per day was based on the patient's body surface area as follows: $<1.25 \mathrm{~m}^{2}, 80 \mathrm{mg} ; 1.25-1.50 \mathrm{~m}^{2}, 100 \mathrm{mg} ;>1.5 \mathrm{~m}^{2}, 120 \mathrm{mg}$. Treatment was continued until one of the following occurred: progressive disease, treatment was not resumed even after 28 days from the last administration, administration difficulty due to adverse effects, or decision to stop treatment at the discretion of the treating physician.

Ethics statement. This study was approved by the ethics committee of participating institutions and carried out according to the Declaration of Helsinki.

Statistical analysis. Survival analysis of the group variables was performed using Cox proportional hazards model. The relationship between NLR and other variables were performed using Logistic regression analysis. Analysis was performed using JMP software: $\mathrm{JMP}^{\circledR} 11$ (SAS Institute Inc., Cary, NC, USA).

\section{Results}

Patient's characteristics and chemotherapy. During June 2006 and April 2015, 986 patients underwent gastric surgery at the Department of Surgical Oncology, Osaka City University, Osaka, Japan. A total of 368 patients were diagnosed as pathological stage II/III according to UICC 8th edition. Among them, 187 patients were administered S-1 as postoperative adjuvant chemotherapy. Overall, 15 patients were excluded from the analysis because data were not available, received neoadjuvant chemotherapy and had synchronous cancer (Figure 1). The characteristics of the analyzed 170 patients are summarized in Table I. They consisted of 120 males and 50 females with a median age of 65 years. A total of $109(62.3 \%)$ patients had pathological stage III disease.

The median period of administration was 11 months. 45 (26.4\%) patients discontinued treatment within 6 months mainly due to adverse effects, while $11(6.4 \%)$ patients sustained administration for more than 24 months at their request. Recurrences were observed in 68 patients: peritoneal metastasis $(n=30)$, liver metastasis $(n=11)$, distant lymph nodes $(n=26)$. Discontinuation of $S-1$ due to adverse effects was not associated with progression free survival (PFS). Overall, the 3-year PFS and OS rate was $58.4 \%$ and $68.3 \%$, respectively. The 3-year PFS for patients with stage II was

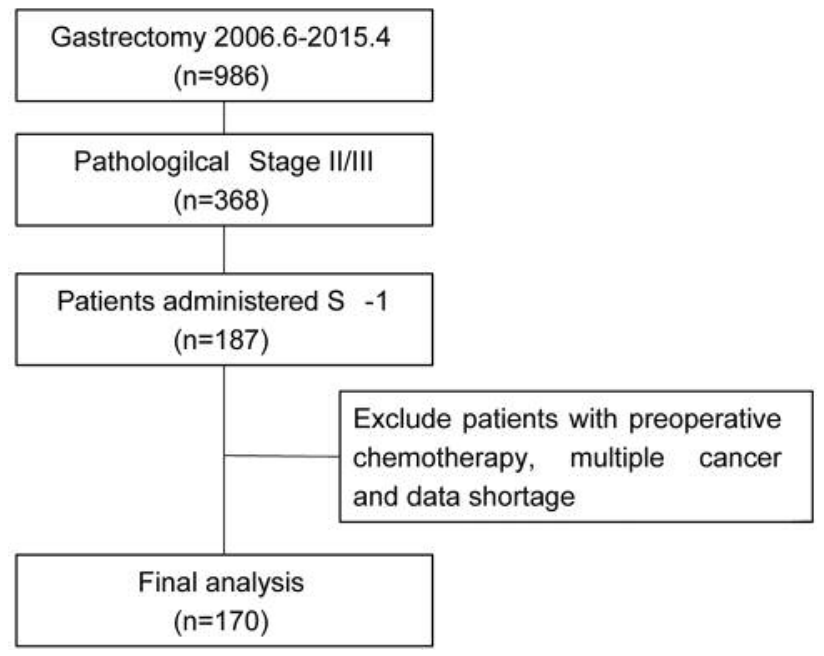

Figure 1. Patient selection.

$74.0 \%$ and for those with stage III was $50.1 \%$. The average of preoperative NLR was 2.5. The number of patients with elevated preoperative CEA and CA19-9 was 37 (21.7\%) and $30(17.6 \%)$, respectively.

Association of postoperative NLR with clinicopathological features. The relation of surgery and NLR value is shown in the time course in Figure 2. On the whole, the NLR value was decreased gradually after surgical operation, suggesting that NLR might reflect inflammatory response against cancer. Patients who had postoperative recurrent diseases had a significantly higher level of NLR than those without recurrence (Figure 2). Median value of NLR preoperatively and at one month, 6 months, 1-year, and 2-years after surgery and at the time of recurrence were $2.12,1.58,1.39$, $1.44,1.49$ and 2.45 , respectively.

Patients were divided into two groups with either high or low values of NLR and PNI based on the cut off vales which were determined using Receiver Operating Characteristic (ROC) Curve analysis. The cut off values of NLR and PNI were 1.99 and 46.2 respectively (Figure 3 ). The summary of correlations of inflammatory indices with patients' characteristics are shown in Table II. Elevation of postoperative NLR was associated with pathological lymph node metastasis. Unlike NLR, PNI and mGPS correlated with age and surgical procedure. Elderly patients and patients that underwent total gastrectomy had lower PNI and high GPS. Pathological lymph node metastasis was common with three indices, NLR, PNI and mGPS. These three factors correlated with each other, and many cases showed high NLR value and low PNI and mGPS 1/2 (Table III). 
Table I. Patient characteristics $(n=170)$.

\begin{tabular}{|c|c|c|c|}
\hline Age & $65 \pm 10$ & Venous invasion & \\
\hline Gender & & Negative & 114 \\
\hline Male & 120 & Positive & 56 \\
\hline Female & 50 & Pathological T & \\
\hline Ope & & pT1 & 7 \\
\hline DG & 92 & pT2 & 28 \\
\hline TG & 78 & pT3 & 50 \\
\hline Macroscopic type & & pT4 & 85 \\
\hline Type 0 & 30 & Pathological N & \\
\hline Type 1 & 9 & pNO & 7 \\
\hline Type 2 & 33 & $\mathrm{pN} 1$ & 28 \\
\hline Type 3 & 81 & $\mathrm{pN} 2$ & 50 \\
\hline Type 4 & 13 & $\mathrm{pN} 3$ & 85 \\
\hline Type 5 & 4 & Pathological Stage & \\
\hline Histology & & pStage II & 61 \\
\hline Differentiated & 73 & pStage III & 109 \\
\hline Undifferentiated & 95 & Recurrence & \\
\hline Lymphatic invasion & & Peritoneal metastasis & 30 \\
\hline Negative & 23 & Liver metastasis & 11 \\
\hline Positive & 147 & Distant Lymph node & 26 \\
\hline & & Other & 4 \\
\hline
\end{tabular}

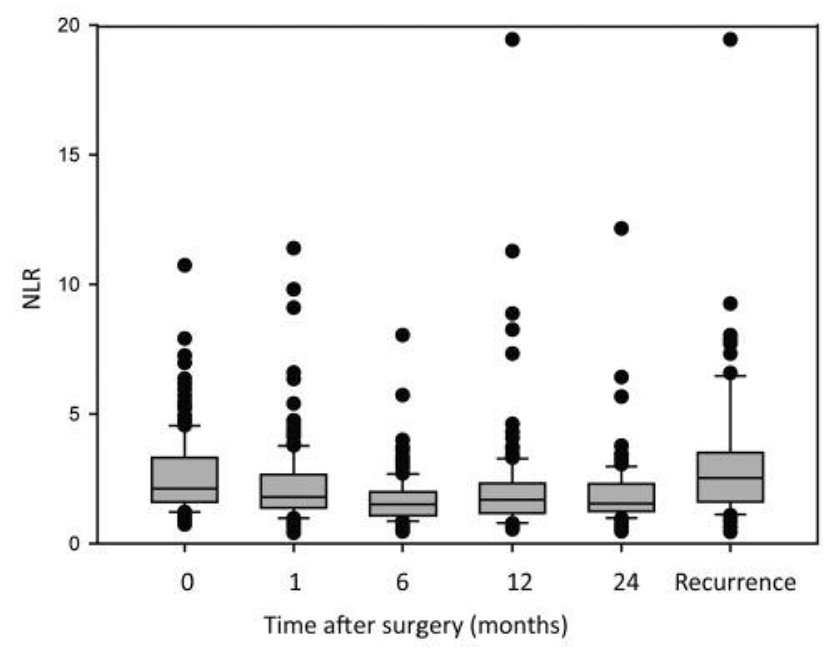

Figure 2. NLR value according to a time course after surgery. The data of each case's NLR at the time of pre-operation, 1, 6, 12, 24 months and at recurrence is shown in the boxplot. The horizontal line at the center of each box shows the median value, and the upper and lower horizontal lines show the third quartile and the first quartile, respectively.

Impact of inflammatory index on progression-free survival. The risk factors for postoperative recurrence were next examined. Univariate analysis revealed that patients with high age $(>75)$, those that underwent total gastrectomy, had $\mathrm{pN} 2 / 3$ or pStage III, had poor prognosis (Table IV). With regard to blood examination, elevation of tumor markers, high GPS, low PNI and high NLR were associated with
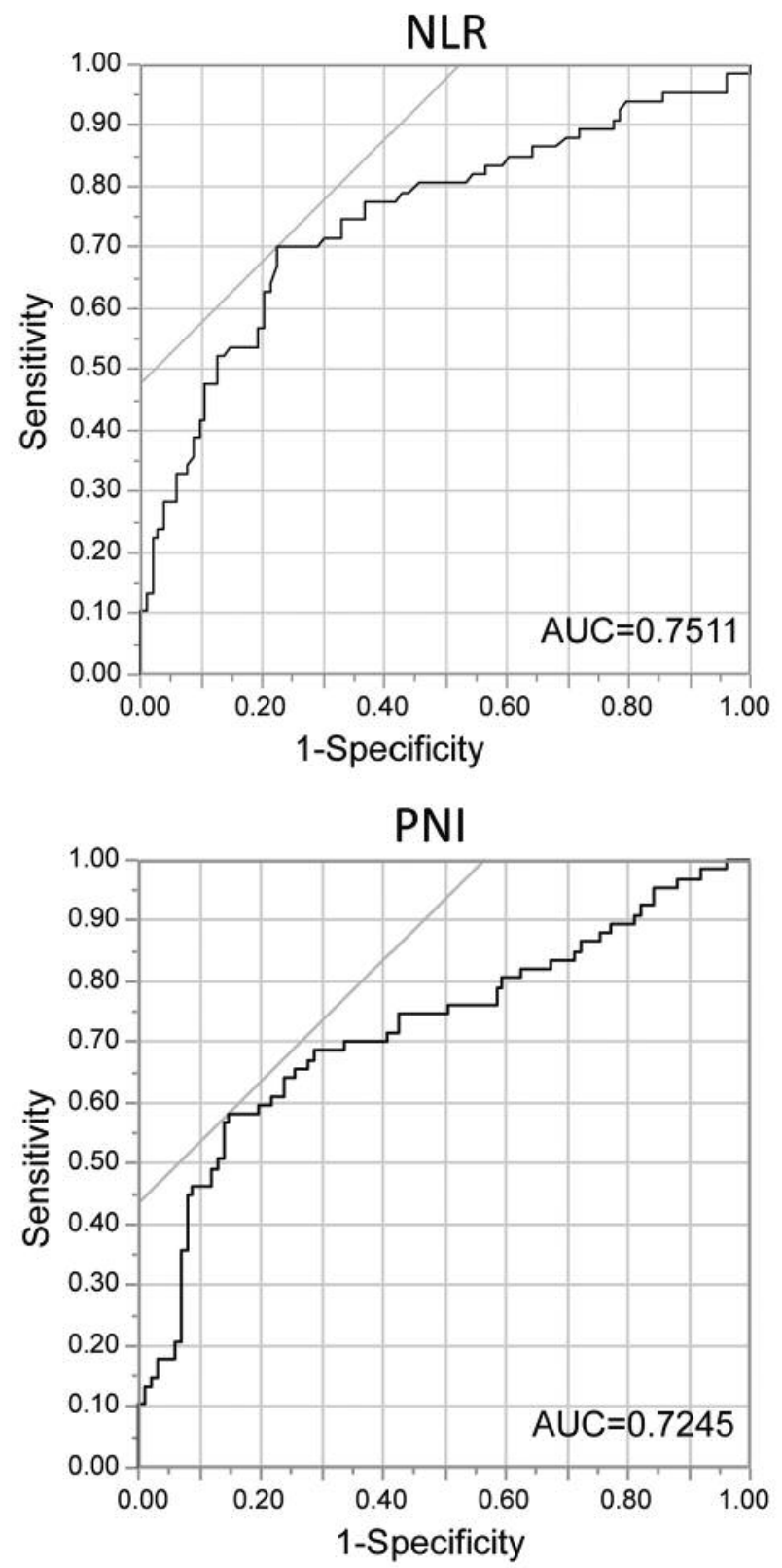

Figure 3. ROC curve of NLR and PNI. The continuous variable density of NLR and PNI were used as the test variable and postoperative recurrence as the state variable. An investigation of the cut-off value score showed the most appropriate cut-off value for the NLR to be 1.99 (AUC; 0.751 , the sensitivity was 0.701 and the specificity was 0.522 ) and for the PNI to be 46.2 (AUC; 0.724, the sensitivity was 0.582 and the specificity was 0.567). Therefore, the cut-off value for analysis was set at 1.99 for NLR and 46.2 for PNI.

postoperative recurrence. Multivariate analysis indicated that total gastrectomy, pStage III, elevated tumor markers and NLR were significantly associated with poor prognosis, but not PNI and mGPS. 5-year progression free survival rate was 
Table II. Association of NLR, PNI and mGPS with clinical background.

\begin{tabular}{|c|c|c|c|c|c|c|c|c|c|}
\hline & \multicolumn{2}{|c|}{ NLR } & \multirow[b]{2}{*}{$p$-Value } & \multicolumn{2}{|c|}{ PNI } & \multirow[b]{2}{*}{$p$-Value } & \multicolumn{2}{|c|}{ mGPS } & \multirow[b]{2}{*}{$p$-Value } \\
\hline & Low & High & & Low & High & & 0 & 1.2 & \\
\hline \multicolumn{10}{|l|}{ Age } \\
\hline$>75$ & 86 & 55 & \multirow[t]{2}{*}{0.205} & 16 & 13 & \multirow[t]{2}{*}{0.0059} & 19 & 10 & \multirow[t]{2}{*}{0.015} \\
\hline$\leq 75$ & 14 & 15 & & 39 & 100 & & 126 & 15 & \\
\hline \multicolumn{10}{|l|}{ Gender } \\
\hline Male & 66 & 54 & \multirow[t]{2}{*}{0.116} & 41 & 79 & \multirow[t]{2}{*}{0.5302} & 103 & 17 & \multirow[t]{2}{*}{0.842} \\
\hline Female & 34 & 16 & & 14 & 34 & & 42 & 8 & \\
\hline \multicolumn{10}{|l|}{ Ope } \\
\hline DG & 57 & 35 & \multirow[t]{2}{*}{0.364} & 19 & 72 & \multirow[t]{2}{*}{0.003} & 85 & 7 & \multirow[t]{2}{*}{0.0045} \\
\hline TG & 43 & 35 & & 36 & 41 & & 60 & 18 & \\
\hline \multicolumn{10}{|l|}{ Macroscopic type } \\
\hline Type $0,1,2,3$ & 93 & 64 & \multirow[t]{2}{*}{0.704} & 47 & 108 & \multirow[t]{2}{*}{0.0265} & 134 & 23 & \multirow[t]{2}{*}{0.139} \\
\hline Type 4 & 7 & 6 & & 8 & 5 & & 11 & 2 & \\
\hline \multicolumn{10}{|l|}{ Histology } \\
\hline Differentiated & 47 & 28 & \multirow[t]{2}{*}{0.356} & 23 & 51 & \multirow[t]{2}{*}{0.684} & 65 & 10 & \multirow[t]{2}{*}{0.404} \\
\hline Undifferentiated & 53 & 42 & & 32 & 62 & & 80 & 15 & \\
\hline \multicolumn{10}{|l|}{ Lymphatic invasion } \\
\hline Negative & 12 & 11 & \multirow[t]{2}{*}{0.485} & 6 & 17 & 0.456 & 20 & 11 & 0.826 \\
\hline Positive & 88 & 59 & & 49 & 96 & & 125 & 14 & \\
\hline Venous invasion & & & & & & & & & \\
\hline Negative & 68 & 46 & 0.755 & 39 & 74 & 0.479 & 99 & 15 & 0.6115 \\
\hline Positive & 32 & 24 & & 16 & 39 & & 46 & 10 & \\
\hline Pathological T & & & & & & & & & \\
\hline $\mathrm{pT} 1 / 2$ & 22 & 13 & 0.586 & 9 & 26 & 0.3119 & 33 & 2 & 0.0609 \\
\hline $\mathrm{pT} 3 / 4$ & 78 & 57 & & 46 & 87 & & 112 & 23 & \\
\hline Pathological N & & & & & & & & & \\
\hline $\mathrm{pN} 0 / 1$ & 47 & 22 & 0.0419 & 16 & 52 & 0.0338 & 59 & 10 & 0.0169 \\
\hline $\mathrm{pN} 2 / 3$ & 53 & 48 & & 39 & 61 & & 86 & 15 & \\
\hline Pathological Stage & & & & & & & & & \\
\hline pStage II & 41 & 20 & 0.0964 & 15 & 45 & 0.111 & 51 & 10 & 0.107 \\
\hline pStage III & 59 & 50 & & 40 & 68 & & 94 & 15 & \\
\hline
\end{tabular}

$79.4 \%$ in patients with high postoperative NLR and $33.4 \%$ in those with low NLR $(p<0.0001)$. These differences in the survival rate were recognized in each stage as well (Figure 4A and B). Importantly, patients with low values of both NLR and CEA after surgery had the most favorable prognosis, but patients with high values in both, had a threeyear relapse-free survival rate of $0 \%$ (Figure $4 \mathrm{C}$ ).

\section{Discussion}

In this study, postoperative NLR was found to be an independent predictive factor for patients treated with S-1 adjuvant chemotherapy against stage II/III gastric cancer. In addition, NLR was shown to be useful as a prognostic factor as compared to postoperative PNI and mGPS. Although several studies showed that preoperative elevated value of NLR was associated with poor prognosis, the difference between our study and previous studies is that we examined the relationship between postoperative NLR and relapse.
Table III. Correlation of NLR with PNI and mGPS

\begin{tabular}{lccc}
\hline & Low PNI & High PNI & $p$-Value \\
\hline Low NLR $(\mathrm{n}=100)$ & 12 & 86 & 0.0001 \\
High NLR $(\mathrm{n}=70)$ & 43 & 27 & \\
\hline & mGPS 0 & mGPS $1 / 2$ & $p$-Value \\
\hline Low NLR $(\mathrm{n}=100)$ & 95 & 5 & 0.0001 \\
High NLR $(\mathrm{n}=70)$ & 50 & 20 & \\
\hline & mGPS 0 & mGPS $1 / 2$ & $p$-Value \\
\hline Low PNI $(\mathrm{n}=55)$ & 35 & 20 & 0.0001 \\
High PNI $(\mathrm{n}=113)$ & 108 & 5 & \\
\hline
\end{tabular}

Some cases with Stage II/III had recurrent diseases and the outcome remains insufficient. To predict postoperative recurrence, CEA and CA19-9 measurements are clinically 
Table IV. Prognostic factors.

\begin{tabular}{|c|c|c|c|c|c|c|}
\hline & \multicolumn{3}{|c|}{ Univariate analysis } & \multicolumn{3}{|c|}{ Multiivariate analysis } \\
\hline & HR & $95 \% \mathrm{CI}$ & $p$-Value & HR & $95 \% \mathrm{CI}$ & $p$-Value \\
\hline \multicolumn{7}{|l|}{ Age } \\
\hline $75<$ vs. $75>$ & 2.029 & $1.098-3.53$ & 0.0251 & 1.661 & $0.879-2.95$ & 0.113 \\
\hline \multicolumn{7}{|l|}{ Gender } \\
\hline Male $v s$. Female & 1.301 & $0.766-2.323$ & 0.3383 & & & \\
\hline \multicolumn{7}{|l|}{ Ope } \\
\hline TG vs. DG & 2.359 & $1.448-3.923$ & 0.0005 & 1.751 & $1.023-3.039$ & 0.041 \\
\hline \multicolumn{7}{|l|}{ Macroscopic type } \\
\hline Type $4 v s$. Other & 1.933 & $0.850-3.828$ & 0.1085 & & & \\
\hline \multicolumn{7}{|l|}{ Histology } \\
\hline Undifferentiated $v s$. diff & 1.265 & $0.777-2.104$ & 0.3466 & & & \\
\hline \multicolumn{7}{|l|}{ Lymphatic invasion } \\
\hline Positive $v s$. Negative & 1.658 & $0.778-4.294$ & 0.2053 & & & \\
\hline \multicolumn{7}{|l|}{ Venous invasion } \\
\hline Positive $v s$. Negative & 1.475 & $0.891-2.398$ & 0.1281 & & & \\
\hline \multicolumn{7}{|l|}{ Pathological T } \\
\hline $\mathrm{pT} 3 / 4$ vs. pT1/2 & 1.658 & $0.864-3.591$ & 0.1343 & & & \\
\hline \multicolumn{7}{|l|}{ Pathological N } \\
\hline $\mathrm{pN} 2 / 3$ vs. $\mathrm{pN} 0 / 1$ & 2.154 & $1.277-3.800$ & 0.0035 & & & \\
\hline \multicolumn{7}{|l|}{ Pathological Stage } \\
\hline pStage III vs II & 2.214 & $1.279-4.704$ & 0.0038 & 2.2 & $1.191-4.294$ & 0.011 \\
\hline \multicolumn{7}{|l|}{ Post CEA elevation } \\
\hline Positive vs. negative & 4.29 & $2.626-7.024$ & $<0.0001$ & 2.392 & $1.357-4.211$ & 0.0026 \\
\hline \multicolumn{7}{|l|}{ Post CA19-9 elevation } \\
\hline Positive vs. negative & 5.145 & $2.891-8.771$ & $<0.0001$ & 2.582 & $1.380-4.677$ & 0.0036 \\
\hline \multicolumn{7}{|l|}{ Post mGPS } \\
\hline $1,2 v s .0$ & 4.145 & $2.362-6.994$ & $<0.0001$ & 1.709 & $0.863-3.252$ & 0.119 \\
\hline \multicolumn{7}{|l|}{ Post PNI } \\
\hline Low vs. High & 3.143 & $1.887-5.433$ & $<0.0001$ & 1.235 & $0.617-2.445$ & 0.547 \\
\hline \multicolumn{7}{|l|}{ Post NLR } \\
\hline High $v s$. Low & 4.642 & $2.773-8.059$ & $<0.0001$ & 2.51 & $1.273-4.978$ & 0.008 \\
\hline
\end{tabular}

used, however, the possibility of a false positive or false negative result is high. In this study, we showed that postoperative NLR decreased with time after surgery compared with preoperative NLR but increased at recurrence, indicating that NLR could reflect the tumor as tumor marker. Importantly, the most favorable prognosis was obtained when both NLR and CEA were low. These results suggested that there is a correlation between NLR and CEA.

Host inflammatory response is important in the development and progression of cancer (17). Nutritional status is also associated with prognosis of cancer. It has been reported that remarkable loss of weight after gastrectomy is one of the poor prognostic factors (18). Kiuchi et al. showed that postoperative serum albumin was related with prognosis (19). PNI, which is generally used to assess the nutritional status of patients, has been related with patient prognosis (20). Our results showed that there was a difference between PNI or mGPS and NLR in relation to patient background.
Total gastrectomy and elderly patients had low PNI and high mGPS status. These results suggested that both PNI and mGPS, which were determined based on serum albumin concentration, more strongly reflected the patient's nutritional status than NLR. In this study, multivariate analysis revealed that NLR was associated independently with recurrence free survival. These results indicated that NLR was a more affordable and accessible biomarker compared with PNI or GPS and that immune response or inflammation affected the effectiveness of S-1 adjuvant chemotherapy. NLR can reflect the balance of inflammatory response and immune response. We previously demonstrated the association of intratumor infiltrating neutrophils with poor prognosis in gastric cancer patients (21). There are several reports about the prognostic value of pre-operative or pre-treatment NLR in gastric cancer patients $(22,23)$. This study, which examined the impact of postoperative NLR on response of S-1 adjuvant chemotherapy, is novel compared to previous reports. 
A

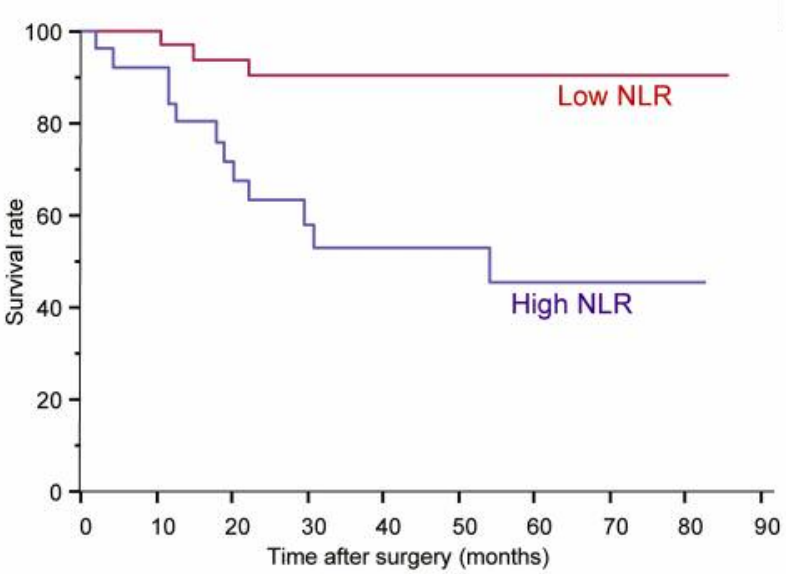

B

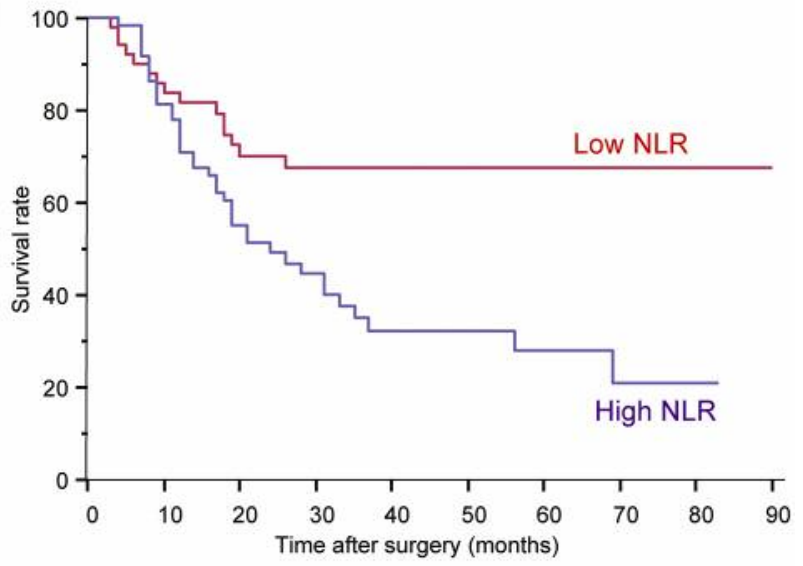

\begin{tabular}{|l|c|c|c|c|c|c|c|c|c|}
\hline No at Risk & & & & & & & & & \\
\hline & 0 & 10 & 20 & 30 & 40 & 50 & 60 & 70 & 80 \\
\hline Low NLR & 35 & 34 & 28 & 22 & 19 & 16 & 11 & 5 & 1 \\
\hline High NLR & 26 & 24 & 17 & 11 & 10 & 7 & 6 & 2 & 1 \\
\hline
\end{tabular}

\begin{tabular}{|l|c|c|c|c|c|c|c|c|c|}
\hline No. at Risk & & & & & & & & \\
\hline Low NLR & 50 & 10 & 20 & 30 & 40 & 50 & 60 & 70 & 80 \\
\hline High NLR & 59 & 48 & 33 & 21 & 11 & 10 & 8 & 4 & 2 \\
\hline
\end{tabular}

\section{C}
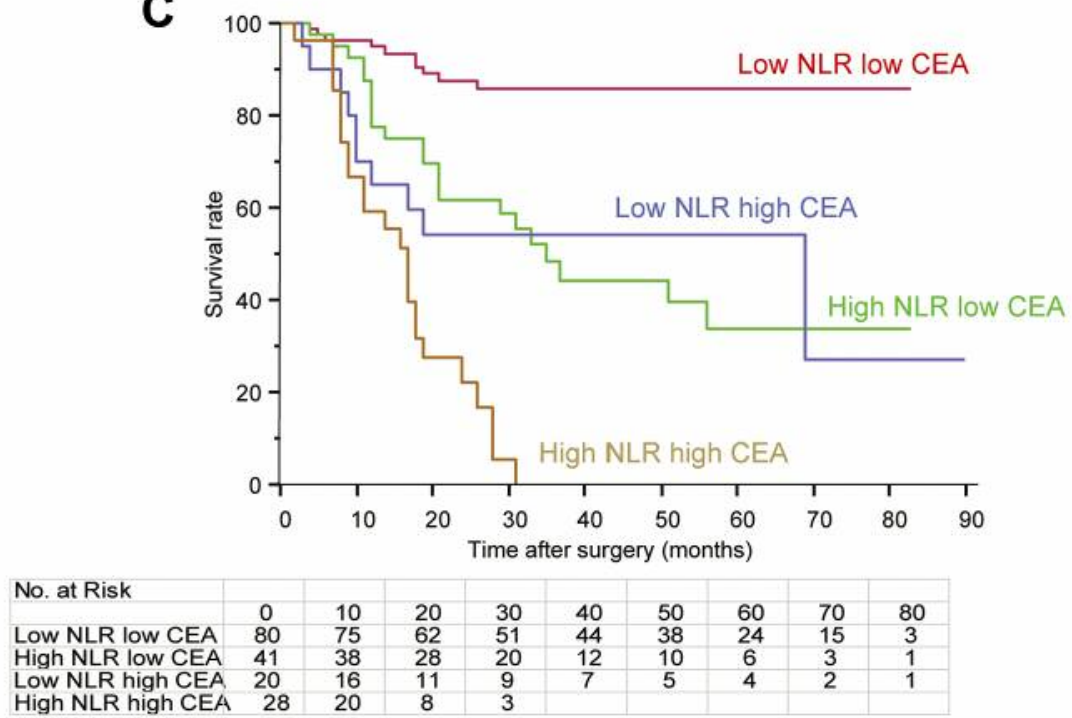

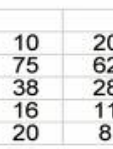

\begin{tabular}{|c|c|}
\hline 20 & 30 \\
\hline 62 & 51 \\
\hline 28 & 20 \\
\hline 11 & 9 \\
\hline 8 & 3 \\
\hline
\end{tabular}

Figure 4. Kaplan-Meier curves of the relapse-free survival that compared NLR high group with low group. A, B) The relapse free survival rate of patients with low NLR was significantly higher than that of patients with high NLR in both stage II (A) and III (B). C) Patients with high NLR and elevated CEA had a much worse prognosis compared to other groups.

On the other hand, there are several limitations in this study. First, this is predominantly an observational study not RCT. Second, further complication to the primary outcome is the known correlation of NLR with other life-threatening condition such as cardiovascular, renal and hepatic diseases. The data of patients with these conditions were included. Third no direct evidence of relationship of NLR with decreased immune response was shown.

In conclusion, NLR might be an attractive biomarker, such as CEA, for predicting recurrence after adjuvant chemotherapy using S-1 for Stage II/III gastric cancer patients.

\section{References}

1 Sakuramoto S, Sasako M, Yamaguchi T, Kinoshita T, Fujii M, Nashimoto A, Furukawa H, Nakajima T, Ohashi Y, Imamura H, Higashino M, Yamamura Y, Kurita A and Arai K: Adjuvant chemotherapy for gastric cancer with S-1, an oral fluoropyrimidine. N Engl J Med 357: 1810-1820, 2007.

2 Sasako M, Sakuramoto S, Katai H, Kinoshita T, Furukawa H, Yamaguchi T, Nashimoto A, Fujii M, Nakajima T and Ohashi Y: Five-year outcomes of a randomized phase III trial comparing adjuvant chemotherapy with S-1 versus surgery alone in stage II or III gastric cancer. J Clin Oncol 29: 4387-4393, 2011. 
3 Katai H, Ishikawa T, Akazawa K, Isobe Y, Miyashiro I, Oda I, Tsujitani S, Ono H, Tanabe S, Fukagawa T, Nunobe S, Kakeji Y, Nashimoto A and Registration Committee of the Japanese Gastric Cancer A: Five-year survival analysis of surgically resected gastric cancer cases in Japan: a retrospective analysis of more than 100,000 patients from the nationwide registry of the Japanese Gastric Cancer Association (2001-2007). Gastric Cancer 21: 144-154, 2018.

4 Wilke H, Muro K, Van Cutsem E, Oh SC, Bodoky G, Shimada Y, Hironaka S, Sugimoto N, Lipatov O, Kim TY, Cunningham D, Rougier P, Komatsu Y, Ajani J, Emig M, Carlesi R, Ferry D, Chandrawansa K, Schwartz JD, Ohtsu A and Group RS: Ramucirumab plus paclitaxel versus placebo plus paclitaxel in patients with previously treated advanced gastric or gastrooesophageal junction adenocarcinoma (RAINBOW): a doubleblind, randomised phase 3 trial. Lancet Oncol 15: 1224-1235, 2014.

5 Kang YK, Boku N, Satoh T, Ryu MH, Chao Y, Kato K, Chung HC, Chen JS, Muro K, Kang WK, Yeh KH, Yoshikawa T, Oh SC, Bai LY, Tamura T, Lee KW, Hamamoto Y, Kim JG, Chin K, Oh DY, Minashi K, Cho JY, Tsuda M and Chen LT: Nivolumab in patients with advanced gastric or gastro-oesophageal junction cancer refractory to, or intolerant of, at least two previous chemotherapy regimens (ONO-4538-12, ATTRACTION-2): a randomised, double-blind, placebo-controlled, phase 3 trial. Lancet 390: 2461-2471, 2017.

6 Takahashi Y, Takeuchi T, Sakamoto J, Touge T, Mai M, Ohkura $\mathrm{H}$, Kodaira S, Okajima K, Nakazato $\mathrm{H}$ and Tumor Marker C: The usefulness of CEA and/or CA19-9 in monitoring for recurrence in gastric cancer patients: a prospective clinical study. Gastric Cancer 6: 142-145, 2003.

7 Perez DR, Baser RE, Cavnar MJ, Balachandran VP, Antonescu CR, Tap WD, Strong VE, Brennan MF, Coit DG, Singer S and Dematteo RP: Blood neutrophil-to-lymphocyte ratio is prognostic in gastrointestinal stromal tumor. Ann Surg Oncol 20: 593-599, 2013.

8 Gregory AD and Houghton AM: Tumor-associated neutrophils: new targets for cancer therapy. Cancer Res 71: 2411-2416, 2011.

9 Grimm M, Feyen O, Hofmann H, Teriete P, Biegner T, Munz A and Reinert S: Immunophenotyping of patients with oral squamous cell carcinoma in peripheral blood and associated tumor tissue. Tumour Biol 37: 3807-3816, 2016.

10 Grenader T, Waddell T, Peckitt C, Oates J, Starling N, Cunningham $\mathrm{D}$, and Bridgewater $\mathrm{J}$ : Prognostic value of neutrophil-to-lymphocyte ratio in advanced oesophago-gastric cancer: exploratory analysis of the REAL-2 trial. Ann Oncol 27: 687-692, 2016.

11 Sierzega M, Lenart M, Rutkowska M, Surman M, Mytar B, Matyja A, Siedlar M and Kulig J: Preoperative neutrophillymphocyte and lymphocyte-monocyte ratios reflect immune cell population rearrangement in resectable pancreatic cancer. Ann Surg Oncol 24: 808-815, 2017.

12 Shibutani M, Maeda K, Nagahara H, Ohtani H, Iseki Y, Ikeya T, Sugano K and Hirakawa K: The prognostic significance of a postoperative systemic inflammatory response in patients with colorectal cancer. World J Surg Oncol 13: 194, 2015.

13 Tanaka H, Muguruma K, Toyokawa T, Kubo N, Ohira M and Hirakawa K: Differential impact of the neutrophil-lymphocyte ratio on the survival of patients with stage IV gastric cancer. Dig Surg 31: 327-333, 2014.
14 Jung M, Ryu MH, Oh DY, Kang M, Zang DY, Hwang IG, Lee KW, Kim KH, Shim BY, Song EK, Sym SJ, Han HS, Park YL, Kim JS, Lee HW, Lee MH, Koo DH, Song HS, Lee N, Yang SH, Choi DR, Hong YS, Lee KE, Maeng CH, Baek JH, Kim S, Kim YH, Rha SY, Cho JY and Kang YK: Efficacy and tolerability of ramucirumab monotherapy or in combination with paclitaxel in gastric cancer patients from the Expanded Access Program Cohort by the Korean Cancer Study Group (KCSG). Gastric Cancer, 2018. doi: 10.1007/s10120-018-0806-1. [Epub ahead of print]

15 Japanese classification of gastric carcinoma: 3rd English edition. Gastric Cancer 14: 101-112, 2011.

16 Dutta S, Going JJ, Crumley AB, Mohammed Z, Orange C, Edwards J, Fullarton GM, Horgan PG and McMillan DC: The relationship between tumour necrosis, tumour proliferation, local and systemic inflammation, microvessel density and survival in patients undergoing potentially curative resection of oesophageal adenocarcinoma. Br J Cancer 106: 702-710, 2012.

17 Colotta F, Allavena P, Sica A, Garlanda C and Mantovani A: Cancer-related inflammation, the seventh hallmark of cancer: links to genetic instability. Carcinogenesis 30: 1073-1081, 2009.

18 Aoyama T, Yoshikawa T, Shirai J, Hayashi T, Yamada T, Tsuchida K, Hasegawa S, Cho H, Yukawa N, Oshima T, Rino Y, Masuda M and Tsuburaya A: Body weight loss after surgery is an independent risk factor for continuation of S-1 adjuvant chemotherapy for gastric cancer. Ann Surg Oncol 20: 2000-2006, 2013.

19 Kiuchi J, Komatsu S, Kosuga T, Kubota T, Okamoto K, Konishi H, Shiozaki A, Fujiwara H, Ichikawa D and Otsuji E: Long-term postoperative nutritional status affects prognosis even after infectious complications in gastric cancer. Anticancer Res 38 : 3133-3138, 2018.

20 Sakurai K, Tamura T, Toyokawa T, Amano R, Kubo N, Tanaka H, Muguruma K, Yashiro M, Maeda K, Ohira M and Hirakawa K: Low Preoperative Prognostic Nutritional Index Predicts Poor Survival Post-gastrectomy in Elderly Patients with Gastric Cancer. Ann Surg Oncol 23: 3669-3676, 2016.

21 Tokumoto MW, Tanaka H, Tauchi Y, Kasashima H, Kurata K, Yashiro M, Sakurai K, Toyokawa T, Kubo N, Amano R, Kimura $\mathrm{K}$, Muguruma $\mathrm{K}$, Maeda $\mathrm{K}$, Ohira $\mathrm{M}$ and Hirakawa $\mathrm{K}$ : Identification of tumour-reactive lymphatic endothelial cells capable of inducing progression of gastric cancer. Br J Cancer 113: 1046-1054, 2015.

22 Yamanaka T, Matsumoto S, Teramukai S, Ishiwata R, Nagai Y and Fukushima M: The baseline ratio of neutrophils to lymphocytes is associated with patient prognosis in advanced gastric cancer. Oncology 73: 215-220, 2007.

23 Hwang GY, Baek DW, Cho HJ, Lee SJ, Chae YS, Kang BW, Lee IH, Kim JG, Seo AN, Bae HI, Park KB, Park JY, Kwon OK, Lee SS and Chung HY: Elevated neutrophil-to-lymphocyte ratio predicts survival in patients with advanced gastric cancer treated with trastuzumab combination chemotherapy. Anticancer Res 38: 3151-3156, 2018.
Received April 19, 2018

Revised May 14, 2018

Accepted May 15, 2018 